\title{
Interaction Between the Tourism Industry and Ecological Environment Based on the Complicated Adaptation System (CAS) Theory: A Case Study on Henan Province, China
}

\author{
Zhong Wei Wang $\dagger$ \\ Yellow River Conservancy Technical Institute, Kaifeng 475004, China \\ †Corresponding author: Zhong Wei Wang; 94381557@qq.com
}

Nat. Env. \& Poll. Tech. Website: www.neptjournal.com

Received: 25-04-2020

Revised: 16-06-2020

Accepted: 13-07-2020

Key Words:

Tourism industry

Ecological environment Interactive relationships CAS theory

\begin{abstract}
Pressure over the destruction of the ecological environment by the tourism industry from the blind development of tourism areas, tourism projects that destroy the ecological environment, tourist overloading during holidays, and poor environmental protection awareness among tourists is increasing. Seeking a balance point between ecological environmental protection and tourism industrial development is key in the sustainable development of the tourism industry. The Complicated Adaptation System (CAS) theory is an important theory in the current system, which focuses on the interaction of the internal elements of a system. Analyzing the interactive development between the tourism industry and the ecological environment based on CAS theory is one way to achieve the harmonious coexistence of the tourism industry and the ecological environment. A case study on Henan Province, China, is conducted, the literature on the interaction between the tourism industry and ecological environment is reviewed, and the environmental pollution status of Henan Province caused by the tourism industry is summarized. Moreover, the complex adaptation of the tourism industry and ecological environment is analyzed. Research results show that most studies support the belief that the tourism industry generates substantial environmental pollution. Environmental pollution from the tourism industry in Henan Province is reflected in tourist overloading, the direct effects of pollution from tourism consumption, damage to cultural relics in star-level tourism areas, and in dwindling habitats for plant and animal survival. Analyzing the interactive relationship between the tourism industry and ecological environment has scientific value and is worth promoting. This relationship is established based on CAS theory from four characteristics, namely, clustering, nonlinearity, flow, and diversity, and three mechanisms, that is, labelling, an internal model, and building blocks. The research conclusions can serve as a reference to better facilitate tourism industry development, estimate the relationship between the tourism economy and ecological environment, and combine ecological tourism and green technological innovation effectively.
\end{abstract}

\section{INTRODUCTION}

The tourism industry is an important component of the modern service industry, which can promote the development of new industries, including ecological tourism, rural tourism, and leisure agriculture. Moreover, the sustainable development of natural ecological environments in tourism destinations can be realized by improving tourism ecological efficiency and promoting ecological protection, thereby achieving interaction between economic development and environmental protection in China. As a "smoke-free industry," the tourism industry is an important direction for local industrial transformation. However, problems in practical development, construction, and tourism activities have emerged, such as the blind development of tourism areas, tourism projects that destroy ecological environments, and tourist overloading during holidays, which can lessen the environmental carrying capacity of tourism areas. Specifically, the most adverse impact of tourism product consumption on local ecology is reflected in ecological environmental pollution and ecosystem damage. Tourists generate pollution during tourism activities. Faeces and the arbitrary disposal of waste, bottles, papers, and tin cans in domestic wastewater can cause ecological environmental pollution. Driven by economic benefits, numerous tourism areas receive tourist volumes beyond their carrying capacity or develop tourism measures without permission from relevant authorities. Such activities can damage historical relics with substantial historical cultural value or unique and coordinated natural and human landscapes. Tourism suppliers may generate environmental pollution owing to "waste gas, wastewater and waste residues" and the improper layout of tourism service facilities during development, construction, and operation. The surge in population facilitates crowding 
and chaos, and tourist destructive behaviour can generate environmental pollution and cause damage. Soil properties deteriorate from being trampled on by numerous people, and lingering tourist populations consume products, natural resources, and energy reserves. Moreover, population concentrations can lead to atmospheric, noise, and visual pollution.

Henan Province is an agricultural province in China with a relatively small population. The province expands its tourism industrial scale continuously by taking advantage of its agricultural industry and tourism resources. After continuous development for nearly 30 years, the tourism industry in Henan Province, especially the rural industry, has formed a preliminary scale. Moreover, Henan Province is an important tourism area owing to its 5,000-year history, cultural artefacts, and unique resources. Nevertheless, the development of the tourism industry in Henan Province has experienced serious challenges in recent years. The development of cultural tourism, which is a subject of tourism products, has slowed down significantly and even halted. Tourism products generate serious environmental pollution and lack the integration of tourism resources. Moreover, the public demonstrates low enthusiasm and environmental protection awareness and lack of responsibility toward tourism environmental resources, thereby influencing environmental pollution in the tourism process. Tourists are direct contributors to environmental pollution in tourism areas during holidays owing to experienced difficulties in parking, eating, defecting, and resting. Selecting a balance point between tourism industry development and environmental protection involves the entire tourism industry development process. Thus, how to address the conflict between industry development and environmental protection in tourism development and realize the sustainable development of the tourism industry and effective protection of the ecological environment should be investigated further.

\section{PAST STUDIES}

The tourism industry is an important component of the modern service industry. Tourism ecological efficiency can be improved by new industries, including ecological tourism, rural tourism, and leisure agriculture. However, problems exist in tourism industry development, such as the blind development of tourism areas, tourism projects that destroy ecological environments, and the reduction of ecological environmental capacity owing to tourist overloading during holidays. As a result, studies focus mainly on the interactive relationship between tourism and the environment. With respect to the interactive relationship between the tourism industry and ecological environment, Butler (1991) believed that the tourism industry and relevant developments impact the environment of "tourism destinations." Owing to a general lack of knowledge, responsibility, and long-term environmental protection planning, the development of numerous tourism areas conforms neither to the environment nor culture of host countries and communities. He et al. (2003) investigated wetland resources in south Dongting Lake and its tourism value and established an evaluation system for the ecological landscape. Moreover, the authors conducted qualitative and quantitative assessments on the value of the wetland landscape to ecological tourism and proposed a principle and framework for the sustainable development of the wetland landscape. Mclennan et al. (2012) discussed the relationship between the economy, society, and environmental indices from three major transformation stages of the tourism industry. Based on a survey of 303 residents in three regions, the authors found that the residents are in different stages of economic development and tourism dependence and thus formulated different tourism, economic, social, and environmental indices. Jinhe et al. (2012) believed that tourism wastes are by-products of resource consumption and environmental digestion and exert environmental and ecological impacts. For example, for the Huangshan National Park in China, the environmental Kuznets curve fit of tourism wastes was tested based on time series data from 1979 to 2010. The results showed that solid-liquid waste emissions from tourists have an environmental Kuznets inverted U-shaped relation with tourism industrial development. Tang et al. (2014) discussed the influence of tourism traffic, accommodations, and activities on total $\mathrm{CO}_{2}$ emissions from the tourism industry in China from 1990 to 2012 using the top-down method. Cao et al. (2016) investigated large invertebrate communities in nine lakes at the Jiuzhaigou Natural Reserve and found that with the increase of populations and acceleration of urbanization, tourism activities in natural protection zones and other natural reserves exert serious impacts on the ecological environment of animals. Based on the statistical data of 11 provinces (cities) in China's Yangtze River, Zhou. Cheng et al. (2016) established an assessment system for the regional economy, ecological environment, and tourism industry and evaluated the development levels of the three systems using the weighted TOPSIS method. The authors concluded that the regional economy is highly associated with the tourism industry of provinces (cities), but no evident contradiction exists between environmental protection and economic development. Fan et al. (2017) pointed out inadequate tourism resources or poor tourism resource development in different regions, which fail to promote the development of the tourism industry and cause serious damage to local natural ecological environments, thereby resulting in blind and excessive development. Moreover, based on the environmental bearing capacity of tourism landscapes, the authors analyzed the 
impact of tourism resource development on the ecological environment and proposed a strategy for sustainable development. Chenyu et al. (2018) constructed a measurement model to assess coordinated development levels and analyze the relevant spatiotemporal evolution model for the period of 2000-2016 based on 14 cities in Gansu Province, China. The authors concluded that ecological environmental development generally lagged behind the tourism industry and economic growth from 2000 to 2016, and the three systems failed to realize synchronous coordinated development. Lopez (2018) believed that the tourism industry is one of the biggest contributors to the gross domestic product of Thailand and suggested the design of a sustainable tourism policy framework with considerations on the sustainable ecological environment. Coordination between public and private sectors may also facilitate the sustainable development of the tourism industry. Schmitz et al. (2018) analyzed the interaction between the environment and coastal tourism industry from the perspective of social-ecological networks and found that social ecosystems in coastal regions are weakened substantially owing to tourism industry development. Liu et al. (2019) analyzed spatiotemporal coupling features between the tourism industry, urbanization, and ecological environment of cities in Shanxi Province for the period of 2000-2017. The research results showed that before 2010, ecological environmental factors dominated the coupling of the urban tourism industry, urbanization, and ecological environment in Shaanxi Province. However, urbanization and the tourism industry became the dominant factors in the coupling development of the three systems after 2010. Zhao et al. (2019) designed an index system for tourism environmental capacity for Pingdingshan City and calculated and examined the tourism environmental capacity of the city. According to the research results, the ecological tourism resource development in Pingdingshan City has advantages of natural conditions, convenient traffic, and perfect infrastructures. However, several problems, such as inadequate resource protection, an unscientific management system, and so on, remain. Yuxi et al. (2020) proposed an international conflict trend predictor (ICTP) between nature-based tourism development and ecological protection and analyzed the spatial distribution features of the ICTP in the study area in China. The results showed that the ICTP level is relatively low or moderate in most regions in China, thereby indicating that most regions suffer from ecological problems caused by natural tourism activities. Based on the above literature review, though the tourism industry drives economic development, it also generates heavy environmental pollution owing to excessive tourism resource development, tourism product consumption relative to environmental carrying capacity, and the coarse commercialization of tourism products. Existing studies on the interaction between tourism industry development and ecological environment protection mainly discuss the linear relationship between tourism industry development and ecological environmental changes by designing a single index system. Besides, such studies do not assess the integral relationship between tourism and the environment from the perspective of comprehensive system theory. Moreover, studies on the interactive development of tourism and the environment as well as evolution mechanisms are inadequate. Hence, an analytical framework for the interactive development of the tourism industry and ecological environment is constructed based on the complicated adaptation system (CAS) theory. Furthermore, a case study on Henan Province, China, is conducted to interpret the evolutionary path of the interactive development of the tourism industry and the ecological environment from a new research perspective.

\section{ENVIRONMENTAL POLLUTION STATUS OF HENAN PROVINCE FROM THE TOURISM INDUSTRY}

\section{Tourist Overloading}

A good environment is a basis for the creation and development of the tourism industry. Moreover, such an environment is the most fundamental condition for the existence and development of the tourism industry in a country or region. However, tourism environments are vulnerable, and tourism development causes environmental damage and impact. Tourism development is viewed as an economic activity, and the pursuit of economic benefits is emphasized, whereas the universal impact of tourism on the environment is neglect. Tourism areas in Henan Province are operating under overloaded capacities, which can destroy the natural ecosystem equilibrium in tourism regions significantly. Fig. 1 shows that from 2010 to 2017, the total number of tourists in tourism areas in Henan Province increased continuously and reached 235 million in 2017. Overcrowding in tourism areas in Henan Province also increased local infrastructure burden, causing water and electricity supply shortages and traffic owing to the sudden rise in demand. Also, high concentrations of tourists in tourism areas in Henan Province during the peak tourist seasons destroyed local habitats and environments for wild animals and plants owing to poor control. Such overloading operations caused serious damage to vegetation and generated heavy environmental pollution in tourism areas, thereby lowering tourism area attraction and shortening service life significantly.

\section{Tourism Consumption Leading to Direct Environmental Pollution}

Tourism activities are consumption-based dynamic behav- 


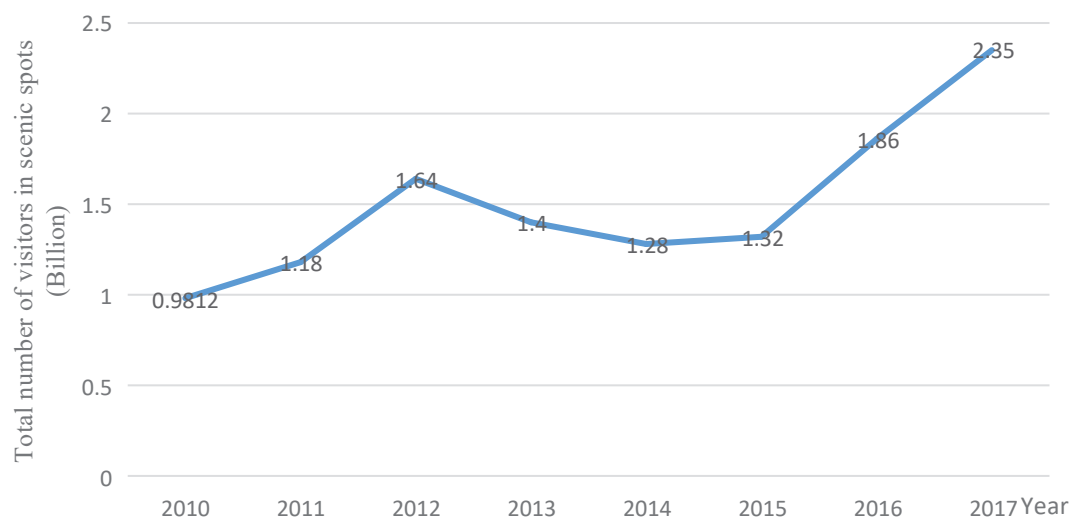

Fig. 1: Number of tourists in tourism areas in Henan Province during the period of 2010-2017 (100 million).

(Data source: EPS dataset: http://olap.epsnet.com.cn/)

iours. The number of foreign tourists staying overnight at Henan Province has increased continuously in recent years. Figure 2 shows the per capita daily cost for foreign tourists and that the number of received foreign tourist staying overnight increased rapidly every year. Tourism activities directly generate environmental pollution. Although administrative departments install garbage bins in tourism areas, many tourists with low personal qualities dispose of their garbage, such as drink bottles and food packages, arbitrarily, which can destroy natural landscapes and pollute scenic spots. As the number of tourists increases, the number of restaurants and hotels near scenic spots likewise increases. This development increases pressure on the tourism environment because tourists' daily activities intensify water pollution. Heavy traffic is a fundamental consequence of tourism. In addition, abundant wastes from traffic, excessive use of air conditioners, and emissions from heating sources can cause air pollution. Moreover, noise generated by vehicles and tourist activities is also a type of environmental pollution.

\section{Damage to Cultural Relics in Star-Level Tourism Areas}

Henan Province has a long history, valuable cultural artefacts, and rich tourism resources. According to Table 1, the number of star-level tourism areas and operating revenue of tourism areas in Henan Province increased continuously from 2011 to 2017. However, some tourists with low cultural qualities fail to recognize the value and uniqueness of cultural relics in star-level scenic areas and engage in various uncivilized behaviours, such as carving characters and pictures on cultural relics, sitting or lying on cultural relics to take pictures, removing cultural relics, and so on. Such actions can incur losses and damage cultural relics to a certain extent. While sightseeing, tourists trample on cultural relics, thereby destroying them, and increased $\mathrm{CO}_{2}$ emissions may erode cultural relics owing to the abundant water content of $\mathrm{CO}_{2}$.

\section{Dwindling Habitats for Animal and Plant Survival}

Certain regions in Henan Province adopt scale development in constructing artificial scenic spots to develop tourism resources, thereby causing excessive deforestation. Such activities cause serious damage to natural landscapes and plant vegetation. Many tourists walk through planted areas or sit on lawns to rest, thereby influencing the normal growth of plants. Thus, the development of tourism areas may destroy the habitats or shelters of wild animals. Tourism activities and noise made by tourists in tourism areas can disturb the life and reproduction of wild animals. In some wildlife parks, tourists often throw their food wastes to animals directly, which can threaten animal survival.

\section{CAS ANALYSIS OF TOURISM INDUSTRY AND ECOLOGICAL ENVIRONMENT}

CAS theory is one of the most important theories in the current system. This theory argues that system evolution is a complex phenomenon, in which the microscopic subjects of a system interact and gradually form macroscopic layers. The concept of CAS theory differs from that of traditional system theory because it emphasizes the interaction of internal factors in a system. According to the relevant concept, CAS theory has seven basic features, including four characteristics (i.e., clustering, nonlinearity, flow, and diversity) and three mechanisms (i.e., labelling, an internal model, and building blocks). In the following section, the interactive relationship between the tourism industry and the ecological environment is analyzed based on the aforementioned seven basic features.

Clustering: In the interaction between the tourism industry 
Table 1: Number of Star-level tourism areas and operation revenues in Henan Province for 2011-2017.

\begin{tabular}{|c|c|c|c|c|c|c|c|}
\hline & 2011 & 2012 & 2013 & 2014 & 2015 & 2016 & 2017 \\
\hline Total number of tourism areas (areas) & 235 & 251 & 257 & 243 & 362 & 385 & 412 \\
\hline Number of AAAAA tourism areas (areas) & 8 & 8 & 9 & 10 & 11 & 12 & 13 \\
\hline Number of AAAA tourism areas (areas) & 81 & 89 & 84 & 74 & 124 & 134 & 146 \\
\hline Number of AAA tourism areas (areas) & 103 & 109 & 110 & 101 & 133 & 141 & 163 \\
\hline Number of AA tourism areas (areas) & 43 & 45 & 54 & 58 & 94 & 97 & 89 \\
\hline Number of A tourism areas (areas) & 0 & 0 & 0 & 0 & 0 & 1 & 1 \\
\hline Operation revenue of tourism areas (100 million yuan) & 38.4 & 91.1 & 104.31 & 98 & 82.91 & 101.06 & 110.09 \\
\hline
\end{tabular}

(Data source: EPS database: http://olap.epsnet.com.cn/)

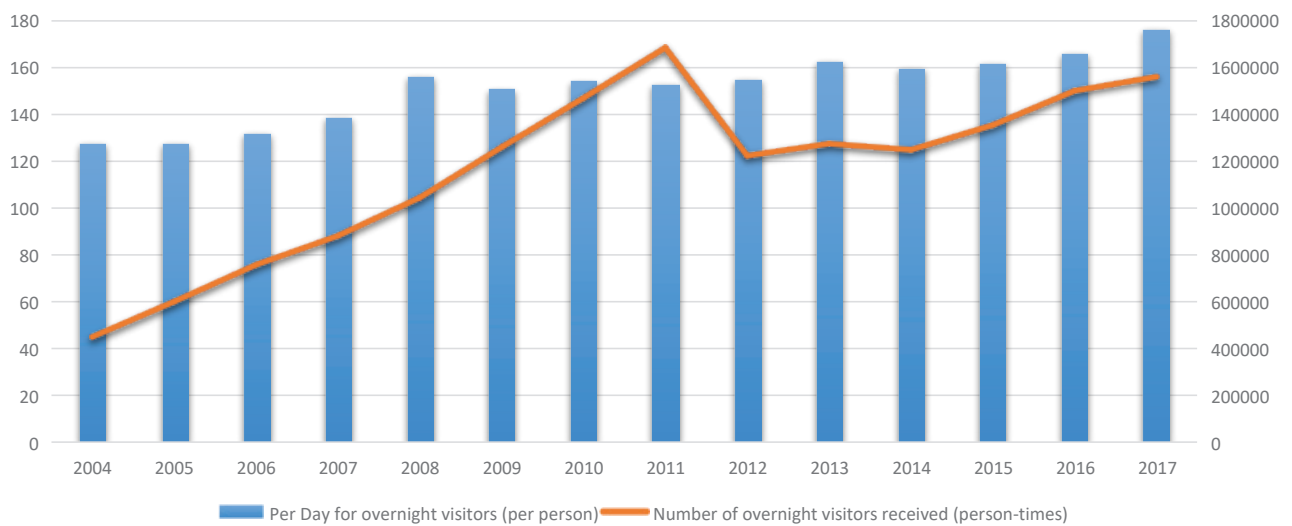

Fig. 2: Per capital daily cost for foreign tourists in Henan Province during the period of 2004-2017. (dollars/people/day), and the total number of received foreign tourists (person) (Data source: EPS dataset: http://olap.epsnet.com.cn/)

and the ecological environment, clustering has two layers of meaning. The first layer is at the primary stage of interaction, in which relevant subjects in different systems cluster and interact actively to realize their development. For example, subjects related to tourism industry development, such as tourism resources, tourism management, tourism hardware facilities, and tourism services, gather in the tourism industry system and coordinate mutually to promote the development of the tourism industry. The influence of ecological tourism subjects on green technological innovation and their benefit pursuits vary to a certain extent. The government mainly influences green technological innovation through policies, and its benefit concerns cover economic benefits, social benefits, and ecological benefits. Meanwhile, the attitude of tourism developers toward green technologies is affected mostly by economic levels, and tourism developers focus on maximizing their economic benefits. Tourism employees focus on their remunerations and social status, whereas communities focus on the improvement of living standards and living environments.
Nonlinearity: A good ecological environment is the foundation of tourism activities and an important impetus that drives the development and progress of the tourism industry. A coupling interactive effect exists between the tourism industry and the ecological environment; however, the internal mechanism of such an effect does not obey a simple linear relationship. According to CAS theory, mutual influences among individuals are complex relations of mutual influences and positive adaption among different interacting systems. In an interaction system, the interactive relationship between the tourism industry system and ecological environment system is formed spontaneously when they seek optimal development. Such an interactive relationship is particularly close in regions with natural resource shortages and vulnerable ecological environments. Diversified subjects are involved in environmental pollution control. The characteristics of the government, social organizations, and ecological tourists are differentiated continuously, and the government has become a subject that provides high-quality public services innovatively. The supervisory function of social organizations 
is strengthened, and the awareness of ecological tourists of their ecological responsibility is further solidified.

Flow: In the interaction system, resource flows between the tourist industry and ecological environment mainly include population flow, material flow, cultural flow, information flow, and capital flow. These resource flows follow a circular pattern in the tourism industry system and ecological environment system and between the two systems. Without external disturbances and increased resource input, resource flows may first go to subjects and systems with high utilization. As a result, resource flows that cannot adapt to system interaction and development will weaken and disappear gradually. Owing to continuous material flows, such as energy and information flows, realizing resource sharing and competence augmentation among subjects in an innovation system, the spillover effect of knowledge, the cumulative effect of innovation, and the "crossing priming effect" of technological innovation is possible. In an innovative network comprising the government, communities, and tourism developers, the subjects are nodes, and resource flows, including technological human resources, capital, and information, generate accumulated experiences and adaptation behaviours.

Diversity: The complexity of adaptation generation is the basic principle of CAS theory. Diversity in the CAS is a type of dynamic reflection showing adaptation and apparent complexity. The tourism industry and ecological environment systems possess the characteristic of diversity. Tourism industry development can be promoted by various factors, including macroscopic factors, resource factors, supply-demand factors, enterprise factors, and so on. Moreover, tourism industry development does not involve a mode and pathway owing to such factors. Tourism industry development observes the decisive role of the market in resource allocation and the supervision and guidance of the government.

Labelling: Labelling refers to the mechanism formed to promote clustering. Under the labelling mechanism, subjects with a common value orientation and objective gather spontaneously and gradually form the unique characteristics and boundaries of a system. Labelling is key in forming subsystem categories and layer divisions in the CAS. In the interaction between the tourism industry and ecological environment, the different characteristics, development objects, interest demands, resource use modes, and management mechanisms of subjects are direct sources for labels. Specific subjects involved in tourism pollution control have different objectives, demands, professional advantages, and resources, which are direct sources for labels. For example, the institution and policy labels of the government, the product label of tourism developers, and the knowledge label of tourism employees are guidelines for selecting innovative allies, sharing knowledge, and reaching innovative consensus and lay a reasonable foundation for specialization and cooperation. Interaction and connection based on the key labels of subjects form the innovative community label.

Internal model: An internal model is a functional model that solidifies gradually when a complex system responds to external input. With the input of abundant resource flows, such as human resources, capital, and information, the inherent form of high-efficiency resource utilization is formed gradually in the tourism industry and ecological environmental systems and between the two systems. The internal model subjects of a system composed of tourism pollution and environmental control are an entire set of rules and programs for adjusting behaviours to adapt to the environment. Based on previous experiences and knowledge, subjects of tourism environmental governance reflect on their conditions, innovative benefits, the strategies of relevant parties, and national ecological regulations and conduct comprehensive evaluations on the innovation of environmental pollution control, thereby making decisions and performing actions. Similarly, the interaction between the tourism industry and ecological environmental systems has a gradually solidified internal model. For example, guided by tourism industry development, the internal model improves ecological environmental quality, increases environmental governance levels, and enhances the environmental education function through tourism development and activities.

Building blocks: Building blocks comprise the CAS. The complexity of a system is determined by the combination mode of building rocks but is unrelated to the number of building blocks. Diversified combinations exist in and among subjects in the tourism industry system. For example, building blocks participate in coordination between enterprises, community residents, and tourists in the subject system; protection in the ecological environmental system; and coordination between environmental pollution control, development, and utilization. In the process of tourism-induced environmental pollution control, the government, communities, tourism developers, tourism employees, social organizations, and ecological tourists are the basic building blocks, and their combination modes in the innovation framework, as well as derived interaction function, play an important role in coordinating economic benefits, social benefits, and ecological benefits and maximizing overall benefits.

\section{CONCLUSIONS}

Owing to unscientific tourism resource development, extensive tourism operations, large-scale waste disposal in the tourism process, and abundant exhaust emissions from tourism vehicles, the tourism industry exerts serious pressure 
on the ecological environment. With reference to CAS theory, investigating the overall interactive relationship between the tourism industry and the ecological environment from the perspective of comprehensive system theory is beneficial to realize the coordinated development of the two systems. A case study on Henan Province, China, is conducted, which summarizes the province's environmental pollution status caused by the tourism industry and analyzes the CAS of the tourism industry and the ecological environment. The research results demonstrate that currently, the tourism industry in Henan Province generates various problems, such as tourist overloading, direct environmental pollution caused by tourism consumption, damage to cultural relics in star-level tourism areas, and dwindling habitats for animal and plant survival. Constructing the interactive relationship between the tourism industry and ecological environment based on CAS theory from four characteristics, namely, clustering, nonlinearity, flows, and diversity, and three mechanisms, that is, labelling, an internal model, and building blocks, has scientific value and is worth promoting. In-depth research on the development of conceptual models for tourism products optimizing the development mode of tourism products, estimating the comprehensive features of the tourism industry and ecological environment, innovating tourism development and environmental control modes, and strengthening tourist participation in tourism-induced environmental protection is necessary.

\section{REFERENCES}

Butler, R.W. 1991. Tourism, environment, and sustainable development. Environmental Conservation, 18(3): 201-209.

Chenyu, L., Wenlei, L., Min, P., Bing, X. and Hong, M. 2018. Quantifying the economy-environment interactions in tourism: Case of Gansu Province, China. Sustainability, 10(3): 711.
Cao, Y., Wang, B., Zhang, J., Wang, L., Pan, Y., Wang, Q., Jian, D. and Deng, G. 2016. Lake macroinvertebrate assemblages and relationship with natural environment and tourism stress in Jiuzhaigou Natural Reserve, China. Ecological Indicators, 62: 182-190.

Fan, S. and Yang, X.Y. 2017. A Study on the impact of tourism resources development on ecological environment. revista de la Facultad de Ingenieria, 32(6): 375-384.

He, P. and Wang, B.Z. 2003. Landscape ecological assessment and eco-tourism development in the South Dongting Lake Wetland, China. Journal of Environmental Sciences, 15(2): 271-278.

Jinhe, Z., Man, L.I., Jing, C., Jing, Z. and Nannan, W. 2012. Analysis of environmental kuznets effect of tourism waste: Case Study of Huangshan National Park. Acta Geographica Sinica, 94(7): 2209-2217.

Lopez, J.C.C. 2018. Sustainable environment and tourism industry: An institutional policy analysis of Northeastern Thailand. Polish Journal of Environmental Studies, 27(1): 31-37.

Liu, J., Li, C., Tao, J., Ma, Y. and Wen, X. 2019. Spatiotemporal coupling factors and mode of tourism industry, urbanization and ecological environment: A Case Study of Shaanxi, China. Sustainability, 11(18): 4923.

Mclennan, C. L., Pham, T., Ritchie, B. and Moyle, B. 2012. Counter-factual scenario planning for long-range sustainable local-level tourism transformation. Journal of Sustainable Tourism, 20(6): 801-822.

Schmitz, M. F., Arnaiz-Schmitz, C., Herrero-Jauregui, C., Díaz Rodríguez P., Gaspar Garcia de Matos, D. and D Pineda F. 2018. People and nature in the fuerteventura biosphere reserve (Canary Islands): socio-ecological relationships under climate change. Environmental Conservation, 45(1): 20-29.

Tang, Z., Shang, J., Shi, C., Liu, Z. and Bi, K. 2014. Decoupling indicators of $\mathrm{CO}_{2}$ emissions from the tourism industry in China: 1990-2012. Ecological Indicators, 46: 390-397.

Yuxi, Z. and Linsheng, Z. 2020. Identifying conflicts tendency between nature-based tourism development and ecological protection in China. Ecological Indicators, 109: 105791.

Zhou, Cheng, Feng, X. G. and Tang, R. 2016. Analysis and forecast of coupling coordination development among the regional economy-ecological environment-tourism industry-A case study of provinces along the Yangtze economic zone. Economic Geography, 36: 186-193.

Zhao, Y. and Jiao, L. 2019. Resources development and tourism environmental carrying capacity of ecotourism industry in Pingdingshan City, China. Ecological Processes, 8(1): 1-6. 